\title{
ОТ ТРАГЕДИИ ИСКУССТВА К ТРАГЕДИИ ХУДОЖНИКА: \\ ФИЛОСОФСКО-ЭСТЕТИЧЕСКИЕ РЕФЛЕКСИИ АЛЕКСАНДРА БЛОКА
}

\section{Е.К. Соболевская}

В начале ХХ века, когда исконно религиозное понятие «теургии» с легкой руки Вл. Соловьева и затем его духовных преемников, младосимволистов, было распространено на сферу художественного творчества, представители религиозной философии, в частности Н.Бердяев и С.Булгаков, неоднократно выказывали свое несогласие в связи с утвердившимся положением вещей и настойчиво заявляли о так называемой трагической безысходности всякого искусства, о его роковом бессилии. Художественное творчество, с их точки зрения, не достигает онтологических результатов - творится идеальное, а не реальное. Искусство есть только путь к обретению красоты, только зов, но при всей своей теургической устремленности, оно все же не в силах «создать жизнь в красоте и тем самым стать подлинно соборным, вселенским» [4, с. 331]; художник волей-неволей творит всего «лишь символические знаки иного бытия, но не допускает самой реальности иного бытия» [1, с. 278].

Именно эта трагическая безысходность искусства, в определенном смысле подтверждающая его онтологическую несостоятельность или же односторонность, как раз и служила тем необходимым камнем преткновения, который, с точки зрения упомянутых выше мыслителей, не позволял распространять понятие «теургии» на сферу творческой деятельности человека. В контексте художественных и философскоэстетических исканий начала двадцатого века, когда искусство, каза-

Актуальні проблеми духовності: зб. наук. праць / Ред.: Я.В. Шрамко

Вип. 10. - Кривий Ріг, 2009, 277-290 
лось бы, действительно ощутило предельную точку своего развития, когда в лице символизма заговорила сама совесть искусства, слова Бердяева и Булгакова звучали как приговор искусству, окончательный и бесповоротный ${ }^{1}$.

Но, по-видимому, так называемая трагическая безысходность искусства не может быть до конца осознана исходя только лишь из той основополагающей аксиомы, согласно которой художник в итоге своей деятельности творит символы, а не саму явно ощутимую реальность. Трагедия искусства глубже, и наибольшая степень проникновения в ее глубины дана только художнику, и, прежде всего, художникусимволисту. Сосредоточим же внимание на тех аспектах художественной деятельности, которые акцентировались самими художниками, и, в частности, Александром Блоком в его публичной речи 1910 года «О современном состоянии русского символизма».

Сам Александр Блок отводил этой речи довольно скромную роль и называл свое слово всего лишь «иллюстрацией» или «конкретизацией» доклада Вяч. Иванова «Заветы символизма». И в определенном смысле речь Блока действительно может рассматриваться в качестве таковой. Но, по моему глубокому убеждению, она представляет собой самостоятельную ценность и не столько иллюстрирует или конкретизирует речь Иванова, сколько необходимо ее дополняет. Поэты высвечивают разные срезы реальности и, соответственно, разные срезы бытия художника в мире. Иванов выявляет природу символического искусства, утверждает «внутренний канон»в качестве основополагающего завета символизма и показывает, что его исполнение обеспечивает наименее безболезненный исход из трагической ситуации разлада между искусством и жизнью. Блок, принимая провозглашенные Ивановым заветы, в высшей степени откровенно свидетельствует о самой трагедии художника-символиста в мире эмпирической обусловленности. Он явственно напоминает о том, на что символизм обрекает и к чему он неминуемо обязывает, и тем самым предостерегает непосвященных от слепого и безответственного подражания теургическому служению художника-символиста.

Прежде всего заметим, что Блок выстраивает свою речь в соответствии с основными принципами диалектики. В качестве тезиса он выдвигает положение о свободе художника в волшебном мире, наполненном соответствиями. Символист - уже изначально теург, ибо он обла-

\footnotetext{
${ }^{1}$ Насколько религиозные философы были правы в своих притязаниях сугубо лишь на однозначное употребление исконно религиозного именования «теургия», это тема отдельного исследования (см.: [10]).
} 
дает тайным знанием мироустройства и видит вещи таковыми, каковы они суть на самом деле. Но поскольку он не просто созерцатель, а все же поэт, он должен воплотить созерцаемое, дать имя открывшейся ему в умном видении реальности, то есть низойти из мира «горнего» в мир «дольний». Здесь, при этом пути «вниз», как раз и начинается переход от тезиса $\kappa$ антитезису, которую в сжатом варианте Блок обозначает как «изменение облика». Художник, переживающий процесс воплощения, по словам Блока, полон многих демонов, или «двойников», из которых «его злая творческая воля создает по произволу постоянно меняющиеся группы заговорщиков». В итоге он добывает искомое. Для самого Блока это искомое - Незнакомка, но она всего лишь - «красавица-кукла», «синий призрак» или, на что немаловажно обратить внимание, «дълвольский сплав из многих миров» [3, с.330] (курсивы мои $-E$. C.).

Искусство, как бы напоминает Блок, не утешает, не утоляет, не насыщает. Оно есть нечто принципиально отличное как от «земли» (дольнего), так и от «неба» (горнего). Трагедия художника состоит не только в том, что он чувствует явный разлад между действительностью, открывшейся ему в опыте творчества, и эмпирикой жизни. Он чувствует также не менее явный разлад между действительностью и тем, что он, освободившись от эмпирики, создает в минуты вдохновения. Он уходит от «дольнего» мира, считая его миром теней, и не досягает «горнего». Он знает об объективном существовании тех миров, которые он посещает, и в то же время видит их призрачность.

Легче всего сейчас, основываясь на признаниях Блока, вновь воспроизвести основную мысль религиозной философии об осознании художником онтологической несостоятельности своего делания, о роковом бессилии искусства, в том числе и искусства символического, и на этом остановиться. Слова Блока действительно могут быть использованы в качестве яркой иллюстрации, подтверждающей вышеприведенные положения. Однако за поверхностным слоем его признаний усматривается другой смысл: другое положение вещей, другая трагедия. И этот смысл по каким-то причинам - возможно, как само собой разумеющееся - не актуализировался критиками символизма.

Так, цитируя свои произведения, Блок говорит: «Это-создание искусства. Для меня - это свершившийся факт. Я стою перед созданием своего искусства и не знаю, что делать. Иначе говоря, что мне делать с этими мирами, что мне делать и с собственной жизнью, которая отныне стала искусством, ибо со мной рядом живет мое создание - не живое, не мертвое, синий призрак. Я вижу ясно „зарницу 
меж бровями туч“ Вакха (,Эрос“ Вяч. Иванова), ясно различаю перламутры крыльев (Врубель - „Демон“, „Царевна-Лебедь“) или слышу шелест шелков (,Незнакомка“). Но все - призрак» [3, с. 331]. И вот, когда художник сознает эту «призрачность», тогда возникают вопросы о проклятии искусства, о «возвращении к жизни», об «общественном служении», о церкви, о «народе и интеллигенции». Но эти поиски, эти временные проклятия искусства, которые знакомы Блоку не из чужого опыта, в свою очередь, приводят художника не к отрицанию так называемых призраков, а к подтверждению их реального существования. Художник с очевидностью обнаруживает объективность и реальность «тех миров». «Все миры, которые мы посещали, и все события, в них происходившие, вовсе не суть „наши представления“», - заверяет Блок [3, с. 331, 332].

Первое, от чего мы можем оттолкнуться, - явная противоречивость мысли Блока: с одной стороны, миры, открывающиеся художнику, призрак, с другой стороны-обгективная реальность. Это противоречие сжато фиксирует саму суть дела, самую сердцевину трагедии художника-символиста.

Насколько я понимаю, когда Блок говорит об изменении облика и о так называемых призраках, он имеет в виду не саму реальность. Неизменность самой реальности в конечном итоге он вряд ли ставит под сомнение. Скорее всего, он актуализирует реальность, как она обнаруживает себя на феноменологическом срезе сознания человека-художника, теряющего необходимую для полноценной творческой жизни установку, ту установку, которая как раз и позволяет ему эту неизменную реальность провидеть, как она есть на самом деле.

Художник-символист действительно, как никто другой, знает о существовании иного мира, иной реальности, или о реалъности реальнейшего бытия, которая не есть мир в его эмпирической данности и одновременно не есть мир «чистых сущностей», находящийся где-то за пределами этого мира, но есть непрерывное осуществление единого как многого и многого как единого. Это знание дано ему в умном видении через опыт художества в качестве знания объективного и достоверного. Или скажем по-другому: художнику-символисту от рождения дано знание мира незримых сущностей. Придя в мир зримый, он не может признать его в качестве мира единственного и самоценного, он ищет в нем подобия, символы мира иного. И в умном видении, через опыт художества, он действительно распознает мир зримый как являюшуюся ноуменальность, как феномен. В единичном событии, в веренице мгновений, беспрестанно сменяющих друг друга, он усматривает 
и схватывает то, что Платон называл эйдосом, или типом бытия, то, что Гете называл первоявлением, или протофеноменом, то, что символисты и Флоренский, памятуя своих великих предшественников, называли символом. Несмотря на различие имен, речь идет, в общем, об одном и том же.

Но опыт художества не может длиться беспрерывно. Он дискретен во времени и безнадежно дискретен и конечен для поэта-лирика. Поэтлирик не то чтобы возвращается в жизнъ, а буквально каждый раз после написания очередного стихотворения выбрасывается в реальность низшего порядка. Точнее, он на время теряет символическую установку (от реального к реальнейшему и от реальнейшего к реальному) и оказывается в самой голой эмпирике жизни, в миру неосвященном, будничном и, в добавление, извращенном трезвой, рассудочной установкой духа. Он оказывается там, где живут суррогаты вещей, указывающие друг на друга и никуда за себя самое не ведущие. И если прежде он дивился лепоте мира и был захвачен таинственностью его смысла, то теперь он дивится его безобразию и отсутствию таинственного зова полноты смысла. Это для символиста - безвоздушное пространство, смерть. И тем не менее, ему нужно каким-то достойным образом здесь находиться и в здешнем принимать участие. Но, зная иное, он слеп и беспомощен в этом своем (по сути, не своем, а чужом, чуждом ему) здесь-нахождении и здесь-участии.

Возвращение художника-символиста в жизнь не означает, однако, полного забвения приоткрывшейся ему в умном видении тайны мироздания. Он знает, что все сущее в его конкретных формах пропитано потенцией символа. И он помнит, что сама эмпирика жизни и сами плоды его художественной деятельности не являются пустой иллюзией, поскольку через опыт художества эта «дольняя» реальность и $я в и$ лась ему во всей очевидности как символ, как феномен, воплощающий ноуменальное в большей или меньшей степени. Но как распознать в эмпирике иное, как распознать ее как феномен, когда она вдруг, с потерей символической установки, перестает восприниматься в качестве таковой!?

Художник-символист живет на границе трансцендентно-имманентного. Его жизнь как целостное событие насквозь диалектична, ибо она развертывается в сфере предельных антиномических понятий. Он как бы разрывается между мирами и ощущает их постоянное несовпадение. Ему открыто переживание высших антиномий души, которые, в свою очередь, отражают высшие антиномии мира. То, что он 
знает как реальнейшее и через опыт трансцензуса как имманентное ${ }^{2}$, будучи погруженным в стихию этого, «дольнего» мира, опознается им как трансцендентное, ибо оно меняет свой лик на личины, на маски. Он обречен на достоверное знание всеединящего ноуменального и на абсурдное существование в мире эмпирической действительности, где истинно реальное становится (представляется) множеством кивающих друг на друга двойников и никогда не совпадает с самим собой.

Для обычного человека, не знающего о реальности реальнейшего бытия (или знающего о нем только в рамках отвлеченного представления) и знающего о мире только как эмпирической, будничной, неосвященной данности, никаких «двойников» и «призраков» нет. А если и есть, к примеру, те же самые художественные образы, то они нереальны, неразличимы как реальные, но различимы как суть представления художника, его субъективного сознания. В то же время художник не-символист в качестве единственной действительной реальности может почитать мир созидаемых им художественных образов, тогда как мир эмпирический для него - суть призрак, неразличимый в качестве реальности. У не-символиста, поскольку ему неведомо переживание высших антиномий действительности, нет и ощущения предельной трагичности, нет очевидного представления Ада жизни. Есть только смутное представление об Аде после жизни и не менее смутное, отвлеченное представление о полноте жизни опять-таки в какойто иной жизни, тогда как художник-символист знает и полноту Ада, и полноту жизни в одной и той же здесъ и сейчас совершающейся жизни.

Трагичность ситуации художника-символиста в мире осложнена следующим обстоятельством. Символизм не был только школой или направлением в искусстве, а символ в конечном итоге не утверждался символистами в качестве простого стилистического приема. Символистом, как говорил Блок, можно было только родиться. И это означало духовное рождение в совершенно иную, новую жизнь. Нельзя стать символистом по собственному желанию, нельзя перестать им по собственному желанию быть. Отказ от символизма - не отказ от определенной позиции художника, но отказ от самого способа бытия. Перестать быть символистом по собственному желанию - то же самое, что и перестать быть по собственному желанию вообще. Таким образом, ни «возвращение в жизнь», ни «общественное служение», ни церко-

\footnotetext{
${ }^{2}$ Трансцендирование - не достижение чего-то трансцендентного, а усмотрение иного, трансцендентного здесъ и сейчас в его очевидности.
} 
вь - словом, все, чем мог бы заняться символист, пытаясь избежать ощущения трагичности из-за постоянного пребывания в сфере трансцендентно-имманентных метаморфоз, практически неосуществимо. И в этом смысле трагедия искусства в символизме достигает действительно предельного выражения.

Потеря символической установки может обернуться для художника-символиста трагедией в ином плане, а именно: если он сознательным или бессознательным образом признает в качестве единственной реальности само искусство. В таком случае он перестанет видеть «небо» и «землю», «горнее» и «дольнее» и самое искусство как «третий», связующий мир. Другими словами, он перестанет различать реальность реальнейшего бытия в качестве непрерывного осуществления единого как многого и многого как единого. В символисте гибнет символист с потерей установки на нераздельность и, одновременно, неслиянность миров. Символист перестает существовать в качестве символиста, когда стираются «границы» искусства.

Поначалу данный путь не представляется гибельным. Художник, как говорит Блок, чувствует себя свободным в мире, полном соответствий. Он искушается их звучной и яркой игрой и все больше и больше отдается их власти. В итоге он оказывается вовлеченным именно в круг соответствий, в круг символических знаков, но уже не символов, не феноменов. Не выдержав искушений, не преодолев искусство как страстно влекущую игру соответствий, художник неожиданно обнаруживает себя в той же голой, адской эмпирике, но уже-эмпирике искусства, где «роза кивает на девушку», а «девушка на розу», и «никто не хочет быть самим собой» ${ }^{3}$.

Творческая воля оборачивается злой волей, когда художник не по соизволению свыше, а по собственному произволу создает «постоянно меняющиеся группы заговорщиков», или «двойников»; они беспрестанно множатся и уже никуда за самое себя не ведут. Трагедия художника, находящегося под властью множества демонов, состоит в том, что он перестает распознавать среди их голосов «единое $\delta \alpha \iota \mu о \nu \iota о \nu »$ тот таинственный внутренний голос, который, по напоминанию Блока, «позволял Сократу безошибочно различать добро и зло», тот голос, который руководил «древним Платоном, созерцателем Идей и средневековым Дантом, мрачным любовником небесной Беатриче» (см.: [2,

\footnotetext{
${ }^{3} \mathrm{~B}$ свое время именно этот уклон символизма послужил основанием для критических замечаний О. Мандельштама (см.: [9, с. 182]). В терминологии Вяч. Иванова такой тип символизма именуется символизмом идеалистическим и отличается от символизма подлинного - реалистического (см.: [5]).
} 
c. 257]).

Блок признает здесь великий грех символизма и свой личный грех. От волшебного мира (тезиса) он пришел к балагану (антитезису), где он играет роль наряду со своими «куклами». Все стало искусством. Все превратилось в одну сплошную хитросплетенную реальность, где провести границу между искусством и жизнью означало бы то же самое, что провести границу между мыслимым и немыслимым.

По-видимому, у современников Блока были основания для следующего вывода: «Призывая нас от „бледных зарев искусства“ к ,пожару жизни", Блок увел нас от подлинного искусства, но не привел к подлинной жизни. Он стал для нас трагическим актером, играющим самого себя. Вместо подлинного (и невозможного, конечно) слияния жизни и искусства явилась жуткая, разрушающая и жизнь, и искусство, сценическая иллюзия. Мы перестали видеть и поэта, и человека. Мы видели маску трагического актера и отдавались гипнозу его игры. [...] Поэзия Блока стала для нас эмоциональным монологом трагического актера, а сам Блок - этим загримированным под самого себя актером», - так писал о судьбе Блока Б. Эйхенбаум [12, с. 556].

Но, констатируя смешение искусства и жизни, я бы воздержалась от таких крайних оценочных суждений, какими переполнена статья Эйхенбаума. Если мы еще можем судить о подлинности или неподлинности художественных произведений, то выносить приговор о неподлинности жизни поэта все же не в нашей компетенции. Уже одно то, что сам Блок неоднократно и - главное - публично судил себя и своих ближайших собратьев по перу за отклонение от истинного пути художника, как раз и говорит о подлинности его жизненной позиции. Воздержалась бы я от таких суждений еще и потому, что трагическая ситуация смешения миров имеет отношение не только к судьбе Блока, не только к судьбе художника-символиста (в узком смысле) и не только к судьбам европейского декадентства. Она проявлялась и проявляется сплошь и рядом.

Не случайно и сам Блок распознает данную ситуацию как присущую художеству в целом. В своем предельном выражении она известна ему на примере судеб Лермонтова, Гоголя, Врубеля, Коммиссаржевской. Назвав эти имена, Блок приходит к следующему заключению: «В черном воздухе Ада находится художник, прозревающий иные миры. И когда гаснет золотой меч, протянутый прямо в сердце ему чьей-то Незримой Рукой - сквозь все многоцветные небеса и глухие воздухи миров иных, - тогда происходит смешение миров, и в глухую полночь искусства художник сходит с ума и гибнет» $[3$, с. 335$]$. 
Одно дело сказать: искусство должно оставаться искусством, жизнь - жизнью, а мир чистых сущностей - миром чистых сущностей. Жизнь и искусство нельзя смешивать, ибо это путь гибельный, но их и нельзя разделять, ибо мы не хотим, в конце концов, чтобы прекрасное по-прежнему в определенном смысле оставалось бесполезным, а полезное - уродливым или безобразным. Разделение искусства и жизни - тоже путь гибельный, пусть и менее в качестве гибели различимый. Но как найти ту «границу» и каким образом на ней удержаться, чтобы искусство и жизнь были нераздельны и неслиянны, чтобы художник не убивал в себе человека, а человек не отказывался от искусства?! На деле все обстоит гораздо серьезнее, и никто из художников, символист он или не-символист, не застрахован ни от смешения миров искусства и жизни, ни от их жесткого разделения.

В связи с проблемой трагичности искусства следует обратить внимание еще на одно положение Блока, которое в данной речи постоянно акцентируется: «Искусство есть Ад»; «в черном воздухе Ада находится художник, прозревающий иные миры»; «искусство есть чудовищный и блистательный $A \partial »$.

На первый взгляд, в этих словах нет ничего удивительного, если принять к сведению древнегреческий миф о прапевце и поэте Орфее и его странствии по мрачному царству Аида в поисках своей возлюбленной. В этих словах нет ничего удивительного, если помнить о Дантовом нисхождении в Ад. Причем и Данте, и Орфей в итоге своего путешествия все же выходят к свету. Блок же, именуя искусство Адом, актуализирует именно его неизбежную связь с губительной, демонической, противоположной свету стихией и актуализирует ее таким образом, что, кажется, ни о каком выходе к свету не может быть и речи. В этом плане не выглядит необдуманным напоминание Блока о злой творческой воле, вершащей произвол посредством постоянного умножения «заговорщиков», «двойников»; не выглядит необдуманным и его признание о добытом в результате творческого процесса образе «ъявольский сплав из многих миров». И, как мы понимаем, эта темная сторона художества как раз и дает о себе знать именно из-за неминуемой связи искусства с демонической стихией, именно из-за неизбежного прохождения художника через сферу иррациональных сил, напряженно противостоящих его сознательным устремлениям.

Слова Блока идут вразрез не только с классической, но и с определенной романтической традицией, согласно которым искусство есть мир «звуков сладких и молитв», спасающий художника от ненавистной ему «прозы» жизни. Предпочитая быть честным до конца, Блок, 
возможно, сам того не желая сознательным образом, восстанавливает в правах известную позицию ортодоксального богословия по отношению к так называемому светскому искусству. В самых общих чертах данная позиция сводится к следующему: всякий деятель искусства, по сути, - актер, лицедей в том смысле, что он умело облекает свои чувства в образы-маски и не обнажает своего единственного, истинного лица. В основе искусства лежит технический трюк, мимезис; искусство - это нисхождение к темным силам, высвобождение темных духов; оно есть творение рук дьявола и его служителей.

Мы можем соглашаться или не соглашаться с вышеприведенным положением. Мы можем искать критерии для дозволенного и недоЗволенного искусства, для искусства истинного, божественного и неистинного, светского. Мы можем вновь и вновь обращаться к главному источнику данной точки зрения - «Государству» Платона и другим его диалогам с целью найти оправдание, скажем, для одинокого поэта-лирика, создающего самый аскетичный в искусстве образ (строчки из букв), а не для актера, воплощающего принцип лицедейства во всей чувственно осязаемой полноте. Мы, наконец, можем по-разному толковать позицию Платона в зависимости от того, является ли он философом-реалистом или философом-идеалистом, как это, к примеру, делает Вяч. Иванов.

«Когда Платон,-уточняет Иванов,-упрекает искусство в том, что оно берет своею моделью не идеи вещей, а самые вещи, делаясь органом только миметической способности человека, он может быть понят двояко [...] Поскольку идеи Платона суть res realissimae, вещи воистину, он требует от искусства столь близкого ознаменования этих вещей, при котором случайные признаки их отображения в физическом мире должны отпасть, как затемняющие правое зрение пелены, то есть требует символического реализма. Поскольку, однако, идеи Платона в истолковании позднейших мыслителей обращаются в ,Понятия“ (Begriffe) в формально-логическом или гносеологическом смысле, постольку эстетика начинает видеть в нем поборника идеалистического искусства, свободного творчества, избавившего себя от счетов с данными как наблюдаемой, так и прозреваемой действительности, от долга верности вещам, познаваемым опытом, равно внешним или внутренним» [5, с. 146-147].

Данное уточнение действительно существенно. Если мы принимаем первое положение, то у нас появляется устойчивое основание считать художника, по крайней мере, художника-символиста, не делателем копии копий, то есть не субъективным пособником дъявольских игр, а 
все же тем, кто созерцает и затем воплощает (высвобождает) вечные, обгективные связи сущего и тем самым поддерживает, укрепляет эти связи; то есть мы можем считать его своего рода теургом. В том случае если мы придерживаемся второй точки зрения, понятно, что ни о каком теургическом действе со стороны человека не может быть и речи. Но существенно данное уточнение, прежде всего, как теоретическое обоснование платформы символического реализма, или искусства единственно должного. И хотя это положение меняет суть дела теоретически, оно не меняет и не устраняет той наличной, предстоящей в живом опыте жизни творческого процесса, о которой так выразительно свидетельствует Блок.

Мы ведь знаем, что и сам Иванов, размышляя о совмещении в художнике двух начал - гения и таланта - определяет гения в качестве «демонической силы», одновременно хранительной и роковой, которая ведет одержимого, как лунатика, и которая нередко способна обратить человека против себя самого (см.: [8, с.75]). Сам Иванов, разделяя дионисийские прозрения Ницше, утверждает творческий акт в качестве события антиномического по своей природе, равно укорененного в двух противоборствующих началах - дионисийском, стихийном, и аполлоническом, божественном.

Мы знаем, что и самому Иванову, уверенно провозглашавшему реалистический символизм как форму художества, базирующуюся на особом способе бытия в мире, были ведомы те хитро сплетающиеся тропы искусства, которые могут окончательно разрушить единство человеческой личности и привести художника к безумию (в буквальном и метафорическом смысле этого слова). Так, описывая творческий процесс, Иванов выделяет его особо опасную сферу, где властвует демоническое, или хаотическое, начало: «Хаотическое, раскрывающееся в психологической категории исступления, - безлично. Оно окончательно упраздняет все грани. Это царство не знает межей и пределов. Все формы разрушены, грани сняты, зыблются и исчезают лики, нет личности». Единственное смягчающее для художника обстоятельство это то, что данная область, как полагает Иванов, находится «по ту сторону добра и зла», она «демонична демонизмом стихий, но не зла» ${ }^{4}$ (см.:

\footnotetext{
${ }^{4}$ Подобное положение вещей в сфере всякого творчества, а конкретнее-в момент перехода из долънего мира в мир горний, утверждается и в работе П. Флоренского «Иконостас». Флоренский довольно подробно описывает те неимоверные трудности, с которыми сталкивается душа воспарившего «путника» по причине отягощающих ее мирских пристрастий, по причине отсутствия или незрелости духовного разума (см.: [11, с.48-49]).
} 
$[7$, c. 30]).

Художник-символист должен быть майевтом: видеть разум явлений и облегчать вещам выявление Красоты; он должен быть открытым для Божественного откровения и являться его носителем и исполнителем. Но это «должен» и даже «является таковым на самом деле» не избавляет, а прямо-таки обязывает нас как можно точнее представить ту трагическую экзистенциальную ситуацию, в которой оказывается художник в момент творческого процесса, когда он, покинув дольний мир, пытается пробиться к созерцанию мира горнего, или же, когда он, покинув горний мир, приближается к миру дольнему. А оказывается он в самом мороке Ада, в какой-то сфере иистой иррациональности, где существует бесчисленное множество миров, где, по словам Блока, «нет причин и следствий, времени и пространства, плотского и бесплотного» (см.: [3, с. 333]). И свойства данной сферы таковы, что попавший в нее, с одной стороны, ощущает полную свободу, тогда как с другой стороны, эта полная свобода угрожает ему безумием или окончательной гибелью (гибелью в качестве художника, а возможно и гибелью в качестве полноценной личности). Единственное, на что он уповает - луч света, «протянутый ему чьей-то Незримой рукой». Гаснет луч света - художник раздавлен иррациональным началом.

Памятуя об онтологическом плане трагедии искусства, который актуализируется религиозной мыслью, мы не должны упускать из виду план экзистенциальный: трагедию внутренней жизни художника. От нее нельзя отгородиться глухой стеной. Искусство есть своего рода испытание, искушение, проверка на «прочность», высвобождение в человеке неведомых сил: и в самом художнике, и в тех, кто ему внимает. Однако признать трагедию искусства на онтологическом срезе в определенном смысле (и тем самым - в определенном смысле его несостоятельность) или же трагический разлад как неизбежное событие внутренней жизни творческой личности не означает признать онтологическую несостоятельность искусства в полном смысле, не означает признать его окончательную трагическую безысходность и роковое бессилие «создать жизнь в красоте и тем самым стать подлинно соборным, вселенским», не означает, наконец, признать, что художник в результате своей деятельности творит «лищъ символические знаки иного бытия». Истинное символическое искусство, или художественный символ, имеет свою специфическую онтологию, а творческая личность, осознавшая неизбежность трагического разлада и при этом находящаяся в поисках цельной жизни, имеет все основания обнаружить в конце концов и возможность исхода из внутренней трагедии. 
Наличие исхода и явственность онтологических оснований искусства тем очевиднее будут заявлять о себе, чем последовательнее и полнее сам художник в процессе своей жизнедеятельности будет исходить из «внутреннего канона»: из свободного и цельного признания «иерархического порядка реальных ценностей, образующих в своем согласии божественное всеединство последней Реальности» (см.: [6, с. 189]). Если художник удержится на грани и не перейдет заповедных пределов, то и сотворенный им символ, образ произведения в целом, не будет расцениваться всего лищъ как символ. Будучи тесно взаимосвязанным с последней реальностью сущего, художественный символ на большее и не претендует. Здесь, в теснейшей взаимосвязи с реальностью высшего порядка, - его онтология, здесь, в способе бытия творческой личности по нормам вселенским, - искомый художником исход.

\section{1 Литература}

[1] Бердяев H.А. Смысл творчества.-M.: АCT; АCT MOCKВА; ХРАНИТЕЛЬ, 2006.

[2] Блок А.А. Генрих Ибсен // Сочинения: В 6 т. - Т. 5: Проза.- М.: Правда, 1971. - С. 250-258.

[3] Блок А.А. О современном состоянии русского символизма // Сочинения: В 6 т. - Т. 5: Проза... - С. 326-336.

[4] Булгаков C.Н. Свет невечерний: Созерцания и умозрения.-М.: Республика, 1994.

[5] Иванов В.И. Две стихии в современном символизме // Иванов В.И. Родное и вселенское. - М.: Республика, 1994. - С. 143-169.

[6] Иванов В.И. Заветы символизма // Иванов В.И. Родное и вселенское... - С. $180-190$.

[7] Иванов В.И. Символика эстетических начал // Иванов В.И. По звездам: Статьи и афоризмы. - СПб.: Оры, 1909. - С.21-32.

[8] Иванов В.И. Спорады // Иванов В.И. Родное и вселенское...C. 73-90.

[9] Манделъштам О.Э. О природе слова // Сочинения: В 2 т. - Т. 2: Проза. Переводы. М.: Худож. лит., 1990. - С. 172-187. 
[10] Соболевская Е.К. Искусство и теургия в философско-эстетической концепции Вячеслава Иванова // Актуальні проблеми духовності: Зб. наук. праць. Вип. 9. - Кривий Ріг, 2008. - С. 323-336.

[11] Флоренский П.А. Иконостас. - М.: Искусство, 1994.

[12] Эйхенбаум Б.М. Судьба Блока // Эйхенбаум Б.М. «Мой временник»... Художественная проза и избранные статьи 20-30-х годов. - СПб.: ИНАПРЕСС, 2001. - С. 554-568. 